\title{
Parathyroid Carcinoma pN1b TNM Finding v8
}

National Cancer Institute

\section{Source}

National Cancer Institute. Parathyroid Carcinoma pN1b TNM Finding v8. NCI Thesaurus.

Code C141073.

Metastasis to unilateral, bilateral, or contralateral cervical (levels I, II, III, IV, or V) or retropharyngeal nodes. (from AJCC 8th Ed.) 